\title{
Accuracy of motor tests related to musculoskeletal fitness as predictors of low back pain in adolescents: a pilot study
}

\author{
Raphael Gonçalves de Oliveira'; Rodrigo Franco de Oliveira²; Anne Karoline Remonte'; Sandy Caroline Garcia'; \\ Cláudia Roberta Brunnquell Sczepanski'; Berlis Ribeiro dos Santos Menossi'; Claudinei Ferreira dos Santos'; \\ Fábio Antônio Néia Martini'; Luciana da Silva Lirani; Laís Campos de Oliveira'
}

\begin{abstract}
Background: The prevalence of low back pain in adolescents is close to that found in the adult population. In view of the relationship between low back pain and the resistance of the spine stabilizing muscles, studies have sought to identify the ability of specific motor tests to predict this condition. Objectives: Our objective was to verify the predictive ability of three motor tests related to musculoskeletal fitness to identify adolescents with low back pain. Methods: The sample consisted of 150 adolescents, of both sexes, aged between 15 and 19 years. The Nordic questionnaire validated for Brazilian adolescents was applied to identify those with low back pain. Subsequently, three motor tests (one-minute sit-up test, Sorensen test and lateral plank test) were applied. Statistical analysis involved the ROC curve, to identify the Area Under the Curve (AUC), assuming a 95\% confidence interval. Results: It was observed in males that all the tests had a low AUC (between 0.56 and 0.57 ), without statistical significance $(p>0.05)$. For females, AUC ranged from 0.62 to 0.66 , with statistical significance $(p<0.05)$ for the cut-off points identified in the one-minute sit-up test ( $\leq 24$ repetitions) and Sorensen test ( $\leq 28$ seconds), however, without significance $(p>0.05)$ for the lateral plank test. Conclusion: Motor tests of abdominal and paravertebral muscle resistance were not predictors of low back pain in male adolescents. Despite the low accuracy, the cut-off points identified in the one-minute sit-up test and Sorensen test, can be used with some caution to predict low back pain in female adolescents.
\end{abstract}

Keywords: Health Criteria; Diagnosis; Physical Fitness; Low Back Pain; Young People.

\section{BACKGROUND}

Low back pain (LBP) is characterized by pain or discomfort in the lower back, which is located below the costal margin and above the gluteal fold, and can radiate to the posterior region of the thigh ${ }^{(1)}$. A systematic review published in 2012, demonstrated a prevalence (overall mean) of LBP in adults of $31 \%$, and could reach $38 \%$ when taken into consideration the last year ${ }^{(2)}$. In the young population, the prevalence is lower, although it reaches approximately $18 \%$ of adolescents between 14 and 16 years of age, reaching $20 \%$ in the 18 -year-old age group ${ }^{(3)}$.

It has been recognized by several studies in the literature that the incidence of LBP at young age is an important risk factor for having LBP in adulthood ${ }^{(4-6)}$. Thus, early identification of LBP may contribute to interventions capable of minimizing the incidence of this condition in adulthood. The main justification is that LBP is the main cause of chronic pain ${ }^{(7)}$, representing the second leading cause of functional disability in the world ${ }^{(8)}$. Besides being a serious welfare problem for people suffering from this condition, LBP has been configured as an important economic problem, generating high costs for the health system ${ }^{(9)}$.

In young population, different factors have been associated with a higher probability of occurrence of LBP, such as participation in competitive sports, female sex, peak growth phase, adverse psychosocial factors, older age, previous history of back injury and history family ${ }^{(10)}$. Although it is believed that the etiology of LBP has different facets, more than $80 \%$ of cases in adolescents occur without apparent physiological motive ${ }^{(11)}$. In view of this, studies have sought to identify other risk factors that may be associated with the incidence of LBP, such as low levels of strength and resistance of the muscles responsible for stabilization of the spine ${ }^{(12-14)}$.

Based on this assumption, some authors have sought to identify the predictive capacity of motor tests related to musculoskeletal fitness, to identify adolescents at higher risk for LBP development ${ }^{(15,16)}$. However, the studies are still incipient and the results are inconsistent, with most motor tests showing a low accuracy for the identification of adolescents

Corresponding Author: Raphael Gonçalves de Oliveira. Centro de Ciências da Saúde, Universidade Estadual do Norte do Paraná, Alameda Padre Magno, 841، CEP: 86.400-000, Jacarezinho, Paraná, Brasil, telefone: +55(43)3525-0498, rgoliveira@uenp.edu.br

1 Universidade Estadual do Norte do Paraná - UENP, Jacarezinho - PR, Brasil

Full list of author information is available at the end of the article.

Financing source: None.

Submission date 05 November 2017; Acceptance date 13 November 2017; Publication date 28 November 2017 
with LBP, especially in boys ${ }^{(15,16)}$. The identification of cut-off points referenced by health criteria, such as LBP, through motor tests related to musculoskeletal fitness, is a relevant alternative that can be used by health professionals in a screening the population of interest, such as the school environment, reaching a considerable proportion of adolescents ${ }^{(17)}$. Therefore, the objective of the present study was to verify the predictive capacity of motor tests related to musculoskeletal fitness to predict the occurrence of LBP in adolescents.

\section{METHODS}

\section{Participants}

The survey was carried out in the municipality of Bandeirantes, in the state of Paraná, Brazil, between April and May 2017. To obtain the sample, we used probabilistic sampling by clusters, taking into account the sex, shift and year of study, in which each adolescent was enrolled in each stratum of the school structure (public and private). In total, six schools were part of the sample. The classrooms chosen were visited by the researchers and the students were clarified about the research objectives, principles of confidentiality, non-identification in the study and of no influence on the treatment they already receive in school if they did not agree to participate in the research.

Participants were excluded from the collection when: a) were under medical treatment; b) used continuous medication; c) underwent surgery less than six months; d) presented musculoskeletal lesions; e) pregnancy. A total of 150 adolescents ( 84 girls), aged 15 to 19 years (mean of $15.8 \pm 1.2$ years) enrolled in public and private high school schools participated in the study. All signed a Free and Informed Consent Form. The study was approved by the Ethics Committee of the Universidade Norte do Parana (Protocol number 1.302.963).

\section{Questionnaire for assessment of low back pain}

The instrument applied in the present study was the adjusted version of a questionnaire widely used to verify LBP in adolescents ${ }^{(16,18,19)}$, proposed by Salminen (personal communication, 1996), derived from a Nordic questionnaire ${ }^{(20)}$, validated for brazilian adolescents by Oliveira et al. ${ }^{(21)}$. The questionnaire includes a design of the lumbar region and defines as LBP any pain or discomfort that occurred during the previous year, unrelated to trauma or menstrual pain. The adolescents were instructed to self-complete the questionnaire and were informed about the willingness of the researchers for possible clarification.

The alternatives of the questionnaire offer two possibilities of answer: "yes" and "no", except for question 4, which offers four possible answers. For this question, the last two alternatives were grouped into a single affirmative response ("yes"), while the first two alternatives were grouped into a single negative response ("no"). Following, the affirmative answers were scored as " 1 " (one) and the negatives were scored as " 0 " (zero). The adolescents who scored $>7$ in the sum of the 15 items of the questionnaire were classified as LBP(21).

\section{Anthropometric variables and motor tests}

In order to determine the body weight measurements, an anthropometric scale with a $10 \mathrm{~g}$ definition was used, while to carry out the height measurements an stadiometer was used with a $1 \mathrm{~mm}$ scale. The body mass index (BMI) was then calculated by dividing the weight by height squared $\left(\mathrm{Kg} / \mathrm{m}^{2}\right)$. Aiming to identify the resistance of the muscles responsible for stabilization of the spine, three motor tests were applied following the $\mathrm{Cox}^{(22)}$ procedures: 1 ) one-minute sit-up test; 2) Sorensen test; 3) lateral plank test. For the one-minute sit up test, the participant was lying supine on a gym mat, knees flexed $\left(90^{\circ}\right)$, feet resting on the ground and hands clasped behind the nape of the neck. The evaluator gripped the participant's feet in order to stabilize them during the test. At the sign of the evaluator, the participant flexed the trunk, until the elbows touch the knees. Upon returning, the participant's back should touch the gym mattress. The number of replicates executed correctly in one minute was recorded.

For the Sorensen test, a examining table was used, in which the participant was in a ventral decubitus with the anterior superior iliac crest aligned with the end of the examining table, so that all the trunk remained without support. The lower limbs were stabilized by the evaluator, so that throughout the test, the participant had to remain with a neutral position of the trunk in relation to the lower limbs. His arms remained crossed against his chest. When the participant left the neutral position or reported back pain, the timer was stopped and the execution time was recorded in seconds.

The lateral plank test was performed on a gymnastic mattress, in which the participant remained in lateral decubitus, with the elbow and forearm resting on the ground and elevated pelvis, making an alignment between head, scapular waist, pelvis, knees and feet. The contralateral upper limb remained positioned at the side of the body, with the elbows extended, while the lower limbs remained positioned one on the other. The participant had the freedom to choose the side of his preference to carry out the test. When the participant left the neutral position or reported pain, the timer was stopped and the run time was recorded in seconds.

\section{Statistical analysis}

The descriptive data were expressed as mean with their respective standard deviation. To verify the normality of the data, the Kolmogorov-Smirnov test was used. Considering that the data presented a non-parametric characteristic, the Mann-Whitney $U$ test was used in the comparison between the sexes for the continuous variables. Pearson's chi-square test was used to compare the prevalence of LBP among boys 
and girls. The determination of the ability of motor tests related to muscle resistance in predicting adolescents with LBP was performed through the global accuracy, identified by the area under the Receiver Operating Characteristic (ROC) Curve, followed by the respective $95 \%$ confidence intervals. The Area Under the Curve (AUC) can range from 0 to 1 with 0.5 (diagonal line) indicating that the motor test has no predictive power and 1 indicating perfect power. For interpretation purposes, AUC values between 0.50 and 0.69 ; 0.70 and 0.89 ; and $\geq 0.90$, were considered low, moderate and high overall accuracy, respectively ${ }^{(23)}$. Cut-off points (criterion) for each motor test with better accuracy were determined by the properties of sensitivity (ability to identify true positives) and specificity (ability to identify true negatives). The data were processed in the SPSS 20.0 program (SPSS Corp., Chicago, IL, USA), except for the ROC Curve procedures, which were processed in the MedCalc 17.5 program (Acacialaan, Ostend, Belgium). The confidence interval for all tests was $95 \%(p<0.05)$.

\section{RESULTS}

Table 1 shows the comparison between the sexes for the study variables. The boys presented significantly $(p<0.01)$ higher values for the anthropometric variables weight and height, and for the one-minute sit-up, Sorensen and lateral plank tests.

The prevalence of LBP was $21.33 \%$ in the whole sample, significantly $(p=0.01)$ higher in females $(28.57 \%$ vs. $12.12 \%)$. Table 2 presents the comparison between adolescents with and without LBP. In relation to the whole sample, a statistically significant difference $(p=0.03)$ was observed for the age variable, which was higher in the group of adolescents with LBP. Adolescents included in this group still showed significantly lower stature $(p<0.01)$ and lower muscle resistance in the three applied motor tests $(p<0.05)$.

When considered only female adolescents, the group with LBP presented significantly $(p<0.05)$ lower muscle endurance for the one-minute sit-up test and Sorensen test, while the lateral plank test presented similar values between the groups. In adolescent males, only the age variable was significantly $(p<0.05)$ higher in the LBP group (Table 2$)$.

Table 3 and Figures 1, 2 and 3 demonstrate the ability of muscle endurance motor tests to predict adolescents with LBP. The highest values of accuracy $(0.64-0.69)$ were observed when considering all samples, regardless of sex, with statistical significance $(p<0.05)$ in all tests, but with a low overall accuracy (AUC $<0.70$ ). The one-minute sit-up test presented good ability to discriminate adolescents with LBP (sensitivity $=84 \%$ ), while the Sorensen and lateral plank tests had good ability to identify adolescents without LBP (specificity $>88 \%$ ).

When stratified by sex, overall accuracy values decreased. In females, AUC ranged from 0.62 to 0.66 , with statistical significance $(p<0.05)$ for the one-minute sit-up and Sorensen tests, however, with no statistical significance $(p=0.09)$ for the lateral plank test. For males, the tests had AUC between 0.56 and 0.57 , with no statistical significance in all cases $(p>0.05)$.

\section{DISCUSSION}

\section{Summary of the main results}

It was the objective of the present study to verify the predictive capacity of three motor tests (one-minute sit-up, Sorensen and lateral plank) to identify adolescents with LBP. The results demonstrated that boys have greater musculoskeletal fitness in the tests considered, while girls have a significantly higher prevalence of LBP. The girls with LBP presented lower results in the one-minute sit-up and Sorensen tests. These same tests were significantly predictors of LBP among girls, despite the low global accuracy. The lateral plank test was not a predictor of LBP in both sexes, in addition, the one-minute sit-up and Sorensen tests were not predictors of LBP in boys.

Table 1. Comparison between boys and girls for study variables.

\begin{tabular}{|c|c|c|c|c|}
\hline Variables & $\begin{array}{c}\text { All } \\
(n=150)\end{array}$ & $\begin{array}{c}\text { Girls } \\
(n=84)\end{array}$ & $\begin{array}{c}\text { Boys } \\
(n=66)\end{array}$ & P* \\
\hline Age (years) & $15.89(1.21)$ & $15.81(1.20)$ & $15.98(1.23)$ & 0.368 \\
\hline Weight (Kg) & $62.80(12.80)$ & $59.13(11.98)$ & $67.46(12.36)$ & 0.000 \\
\hline Height (m) & $1.64(0.08)$ & $1.60(0.06)$ & $1.70(0.06)$ & 0.000 \\
\hline $\mathrm{BMI}\left(\mathrm{Kg} / \mathrm{m}^{2}\right)$ & $23.01(3.85)$ & $22.91(4.11)$ & $23.14(3.53)$ & 0.540 \\
\hline One-minute sit-up test (repetitions) & $26.55(8.71)$ & $22.30(7.40)$ & $31.97(7.13)$ & 0.000 \\
\hline Sorensen test (seconds) & $41.12(14.20)$ & $35.32(11.50)$ & $48.50(13.96)$ & 0.000 \\
\hline Lateral plank test (seconds) & $32.79(14.78)$ & $28.23(12.14)$ & $38.69(15.84)$ & 0.000 \\
\hline
\end{tabular}

Note: Data expressed as mean and standard deviation; *Mann-Whitney U Test; BMI: body mass index. 
Table 2. Study variables between adolescents with and without low back pain.

\begin{tabular}{|c|c|c|c|}
\hline \multirow[b]{2}{*}{ Variables } & \multicolumn{3}{|c|}{ All $(n=150)$} \\
\hline & $\begin{array}{l}\text { Without LBP } \\
\quad(n=118)\end{array}$ & $\begin{array}{c}\text { With LBP } \\
(n=32)\end{array}$ & P* \\
\hline Age (years) & $15.75(1.14)$ & $16.38(1.36)$ & 0.036 \\
\hline Weight (Kg) & $62.95(12.30)$ & 62.25 (14.69) & 0.481 \\
\hline Height (m) & $1.65(0.08)$ & $1.62(0.07)$ & 0.007 \\
\hline $\mathrm{BMI}\left(\mathrm{Kg} / \mathrm{m}^{2}\right)$ & $22.84(3.52)$ & $23.64(4.90)$ & 0.635 \\
\hline One-minute sit-up test (repetitions) & $27.64(8.40)$ & $22.53(8.79)$ & 0.001 \\
\hline Sorensen test (seconds) & $43.01(13.87)$ & $34.16(13.42)$ & 0.002 \\
\hline \multirow[t]{2}{*}{ Lateral plank test (seconds) } & $34.36(14.66)$ & $26.84(13.86)$ & 0.035 \\
\hline & \multicolumn{3}{|c|}{ Girls $(n=84)$} \\
\hline Variables & $\begin{array}{l}\text { Without LBP } \\
(n=60)\end{array}$ & $\begin{array}{l}\text { With LBP } \\
(n=24)\end{array}$ & P* \\
\hline Age (years) & $15.63(1.05)$ & $16.25(1.45)$ & 0.161 \\
\hline Weight (Kg) & $58.56(10.79)$ & 60.57 (14.69) & 0.808 \\
\hline Height (m) & $1.60(0.06)$ & $1.59(0.05)$ & 0.081 \\
\hline $\mathrm{BMI}\left(\mathrm{Kg} / \mathrm{m}^{2}\right)$ & $22.55(3.57)$ & $23.80(5.19)$ & 0.443 \\
\hline One-minute sit-up test (repetitions) & $23.33(7.32)$ & $19.71(7.11)$ & 0.021 \\
\hline Sorensen test (seconds) & $37.12(10.94)$ & $30.83(11.86)$ & 0.024 \\
\hline \multirow[t]{2}{*}{ Lateral plank test (seconds) } & $29.82(11.73)$ & $24.25(12.49)$ & 0.076 \\
\hline & \multicolumn{3}{|c|}{ Boys $(n=66)$} \\
\hline Variables & $\begin{array}{l}\text { Without LBP } \\
(n=58)\end{array}$ & $\begin{array}{c}\text { With LBP } \\
(n=8)\end{array}$ & P* \\
\hline Age (years) & $15.88(1.22)$ & $16.75(1.03)$ & 0.042 \\
\hline Weight (Kg) & $67.48(12.20)$ & $67.30(14.39)$ & 0.867 \\
\hline Height (m) & $1.70(0.06)$ & $1.70(0.08)$ & 0.961 \\
\hline $\mathrm{BMI}\left(\mathrm{Kg} / \mathrm{m}^{2}\right)$ & $23.13(3.48)$ & $23.17(4.17)$ & 0.891 \\
\hline One-minute sit-up test (repetitions) & $32.10(7.04)$ & $31.00(8.17)$ & 0.588 \\
\hline Sorensen test (seconds) & $49.10(14.02)$ & $44.13(13.56)$ & 0.510 \\
\hline Lateral plank test (seconds) & 39.05 (15.97) & $35.71(15.62)$ & 0.575 \\
\hline
\end{tabular}

Note: Data expressed as mean and standard deviation; *Mann-Whitney U Test; BMI: body mass index; LBP: low back pain.

Table 3. Accuracy of motor tests related to musculoskeletal fitness to predict adolescents with low back pain.

\begin{tabular}{|c|c|c|c|c|c|c|}
\hline Motor test & AUC & $95 \% \mathrm{Cl}$ & $\mathbf{P}$ & Sen & Spe & Cut-off Points \\
\hline \multicolumn{7}{|c|}{ All $(n=150)$} \\
\hline One-minute sit-up & 0.69 & $0.61-0.76$ & 0.000 & $84.4 \%$ & $50.9 \%$ & $\leq 27$ \\
\hline Sorensen & 0.67 & $0.59-0.75$ & 0.001 & $37.5 \%$ & $90.6 \%$ & $\leq 28$ \\
\hline Lateral plank & 0.64 & $0.56-0.72$ & 0.018 & $41.9 \%$ & $88.1 \%$ & $\leq 19$ \\
\hline \multicolumn{7}{|c|}{ Girls $(n=84)$} \\
\hline One-minute sit-up & 0.66 & $0.55-0.76$ & 0.009 & $87.5 \%$ & $45.0 \%$ & $\leq 24$ \\
\hline Sorensen & 0.66 & $0.55-0.76$ & 0.022 & $45.8 \%$ & $85.0 \%$ & $\leq 28$ \\
\hline Lateral plank & 0.62 & $0.51-0.73$ & 0.095 & $45.8 \%$ & $83.3 \%$ & $\leq 17$ \\
\hline \multicolumn{7}{|c|}{ Boys $(n=66)$} \\
\hline One-minute sit-up & 0.56 & $0.43-0.68$ & 0.640 & $50.0 \%$ & $72.4 \%$ & $\leq 27$ \\
\hline Sorensen & 0.57 & $0.44-0.69$ & 0.550 & $62.5 \%$ & $67.2 \%$ & $\leq 41$ \\
\hline Lateral plank & 0.56 & $0.43-0.68$ & 0.626 & $28.5 \%$ & $94.8 \%$ & $\leq 19$ \\
\hline
\end{tabular}

Note: 95\% Cl: 95\% confidence interval; sen: sensitivity; spe: specificity; AUC: Area Under the Curve. 

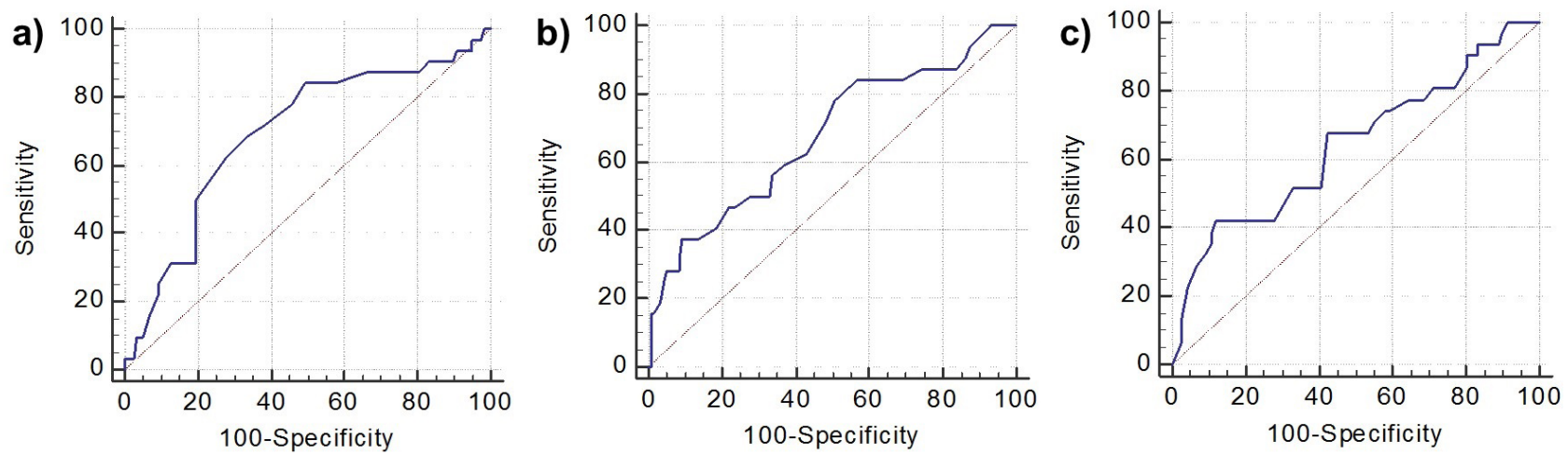

Figure 1. ROC curve of motor tests related to musculoskeletal fitness to predict adolescents with low back pain independent of sex: a) One-minute sit-up; b) Sorensen; c) Lateral plank.
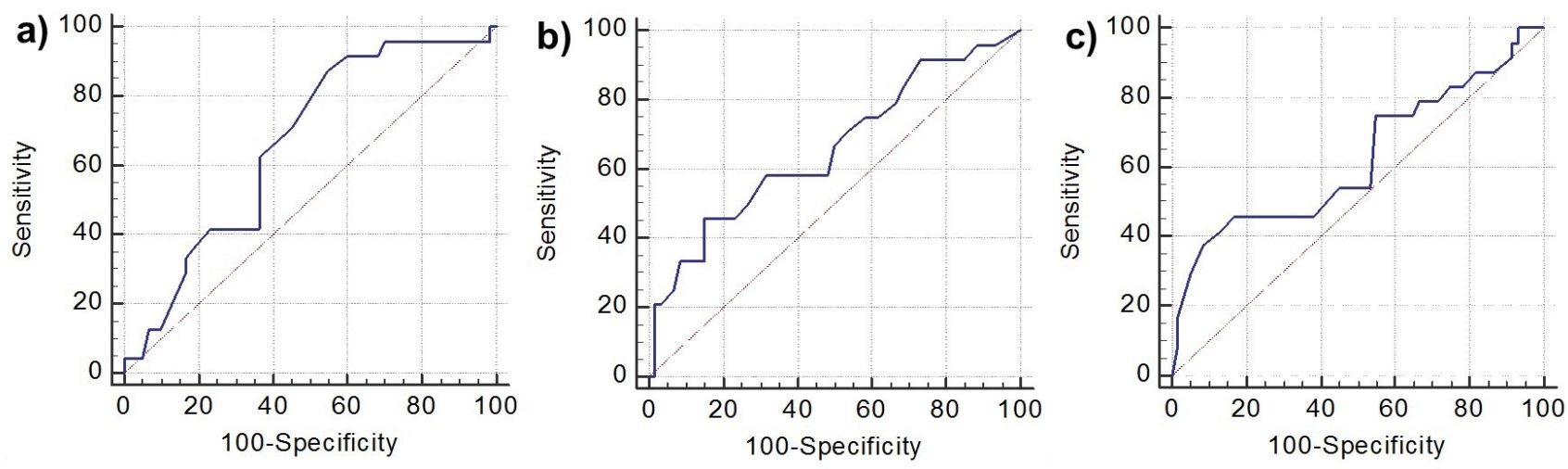

Figure 2. ROC curve of motor tests related to musculoskeletal fitness to predict female adolescents with low back pain: a) One-minute sit-up; b) Sorensen; c) Lateral plank.
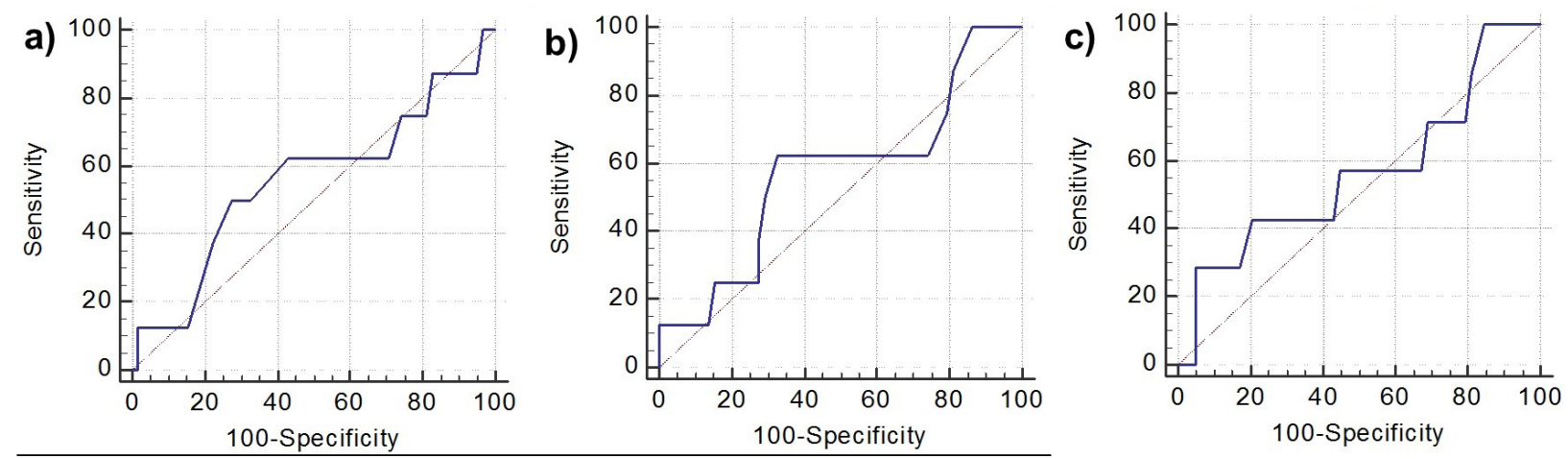

Figure 3. ROC curve of motor tests related to musculoskeletal fitness to predict male adolescents with low back pain: a) One-minute sit-up; b) Sorensen; c) Lateral plank.

\section{Agreements and disagreements with other studies}

In the present study, boys presented higher values of weight and height, as well as, greater musculoskeletal fitness for the motor tests considered. This result was already expected, considering biological factors that differ boys and girls in anthropometric variables, as well as in motor tests involving strength and muscular endurance, which are components of physical fitness that present superior results in males ${ }^{(15,16,24)}$.
A prevalence of $21.33 \%$ of LBP was found in all samples, significantly higher in girls (28.57\%) when compared to boys $(12.12 \%)$. Similar data are found in the literature, where the prevalence of LBP is close to $20 \%$ in adolescents and significantly higher in females ${ }^{(3,15,16,25)}$. When considered as a whole sample, adolescents with LBP presented a significantly higher age, confirming the tendency to increase the prevalence of this condition according to the advancement of age ${ }^{(3,25)}$. However, it is worth noting that when they were stratified 
by sex, older age was significantly observed in adolescents with LBP only in males, which may have occurred because the sample of the present study was relatively homogeneous in relation to the age group. Taking into account the whole sample, adolescents with LBP presented significantly lower performance in all motor tests employed. However, when the sample was stratified by sex, no statistical significance was verified among boys, comparing adolescents with and without LBP. For the female, the results of one-minute sit-up and Sorensen tests remained significantly lower in the group of adolescents with LBP, with no difference for the lateral plank test.

Saint-Maurice et al. ${ }^{(16)}$ when evaluating American children and adolescents, found a significant difference between those with and without LBP only for the dynamic curl-up test, without significant results being observed for other five tests (trunk extension, static curl-up, plank, lateral plank and sit-and-reach) employed to assess musculoskeletal fitness. However, the authors did not perform stratified analysis by sex. Bortolini et al. ${ }^{(26)}$ when evaluating Brazilian children and adolescents, also did not find any significant difference between those classified with and without LBP, for one-minute sit-up and sit-and-reach tests for both sexes. A justification for the lack of significance in the performance of different motor tests related to musculoskeletal fitness among adolescents classified with and without LBP may be linked to a higher level of physical activity among adolescents with this condition. As has been demonstrated in different studies, adolescents with a higher level of physical activity and supposedly with better physical fitness, are more likely to be classified as LBP $(25,27,28)$.

Probably, this factor also limits the hypothesis that motor tests related to musculoskeletal fitness are able to predict a higher risk of LBP among the adolescent population. In the present study, although the motor tests showed significant accuracy when considering the entire sample, or when considering only females (for the one-minute sit-up and Sorensen tests), in all cases, the values presented low accuracy $(A \cup C<0.70)$ to identify adolescents with LBP.

Other studies that had this same goal also found inconsistent results. Dorneles et al. ${ }^{(15)}$ evaluated adolescents between 10 and 17 years of age for one-minute sit-up and sit-and-reach tests, and found a low overall accuracy (between 0.49 and 0.57 ) for predict LBP in both sexes, even though there was statistical significance for the sit-andreach test among the girls. Saint-Maurice et al. ${ }^{(16)}$ analyzed children and adolescents stratified in three different age groups. After administering six tests of musculoskeletal fitness, thus totaling 36 analyzes after stratifying by sex, the majority presented low global accuracy to identify children and adolescents with LBP, except for the sit-and-reach test ( $A \cup C=0.80$ ) among elemental-school girls, static curl-up test ( $A \cup C=0.71$ ) among middle-school girls and dynamic curl-up test $(A \cup C=0.75)$ among high-school boys.
In the current study, even with low overall accuracy, the one-minute sit-up and Sorensen tests presented statistical significance to predict LBP in girls. In this way, the cut-off points identified in these tests can be used with some caution to predict a higher risk of LBP in girls who perform $\leq 24$ repetitions in the one-minute sit-up test or remain $\leq 28$ seconds in the Sorensen test, with a good ability to identify the true positive cases (sensitivity $=87.5 \%$ ) and true negative cases (specificity $=85.0 \%$ ), respectively.

\section{Strengths and limitations}

Considering that so far, few studies have aimed to determine health criteria for musculoskeletal outcomes, the present study collaborates with the discussions on this topic, mainly by contributing to the practice based on evidence, regarding identification of adolescents with a higher risk of LBP. The cut-off points presented here can be used by health professionals to encourage female adolescents to achieve a level of musculoskeletal fitness with a protective effect on the development of LBP. As a limitation, the low number of participants stands out, especially when the analysis is stratified by sex. Finally, another limitation refers to the use of a questionnaire to identify the health outcome investigated (LBP). However, the instrument used is justified by the fact that LBP is a subjective variable, with a multifactorial etiology that is difficult to diagnose.

\section{CONCLUSION}

The results of the present study demonstrated that motor tests of musculoskeletal fitness related to the strength and resistance of the spinal stabilizing muscles, have low accuracy in identifying adolescents with LBP. However, the cut-off points found for the one-minute sit-up and Sorensen tests may be used with some caution in female adolescents, since in spite of the low accuracy, they presented significant results.

\section{AUTHORS' CONTRIBUTIONS}

RGO, RFO, CRBS, BRSM, CFS, FANM, LSL and LCO elaborated the study design. $A K R$ and SCG performed the data collection. RGO performed the statistical analysis. AKR, SCG, CRBS, BRSM, CFS and FANM were involved in the preparation of the manuscript. RGO, RFO, LSL and LCO performed the critical intellectual revision of the manuscript. All authors read and approved the final manuscript.

\section{CONFLICTS OF INTEREST}

The authors declare that they have no conflicts of interest in the research.

\section{AUTHOR DETAILS}

${ }^{2}$ Centro Universitário de Anápolis - UniEVANGÉLICA, Anápolis - GO, Brasil ${ }^{3}$ Universidade Federal do Vale do São Francisco - UNIVASF, Petrolina - PE, Brasil

\section{REFERENCES}

1. Chou R, Qaseem A, Snow V, Casey D, Cross JT Jr, Shekelle P, et al. Diagnosis and treatment of low back pain: a joint clinical practice guideline from the American College of Physicians and the American Pain Society. Ann Intern Med 2007; 147: 478-491. 
2. Hoy D, Bain C, Williams G, March L, Brooks P, Blyth F, et al. A systematic review of the global prevalence of low back pain. Arthritis Rheum 2012; 64: 2028-2037.

3. Jeffries LJ, Milanese SF, Grimmer-Somers KA. Epidemiology of adolescent spinal pain: a systematic overview of the research literature. Spine 2007; 32: 2630-2637.

4. Moreno MA. Low back pain in children and adolescents. JAMA Pediatr 2017; 171: 312.

5. Hestbaek L, Leboeuf-Yde C, Kyvik KO, Manniche C. The course of low back pain from adolescence to adulthood: eight-year follow-up of 9600 twins. Spine (Phila Pa 1976) 2006; 31: 468-472.

6. Feldman DE, Shrier I, Rossignol M, Abenhaim L. Risk factors for the development of low back pain in adolescence. Am J Epidemiol 2001; 154: 30-36.

7. Vos T, Flaxman AD, Naghavi M, Lozano R, Michaud C, Ezzati M, et al. Years lived with disability (YLDs) for 1160 sequelae of 289 diseases and injuries 1990-2010: a systematic analysis for the Global Burden of Disease Study 2010. Lancet 2012; 380: 2163-2196.

8. Allegri M, Montella S, Salici F, Valente A, Marchesini M, Compagnone $C$, et al. Mechanisms of low back pain: a guide for diagnosis and therapy. Version 2. F1000Res. 2016 [revised 2016 Oct 11]; 5. pii: F1000 Faculty Rev-1530.

9. Itz CJ, Ramaekers BL, Van Kleef M, Dirksen CD. Medical specialists care and hospital costs for low back pain in the Netherlands. Eur J Pain 2017; 21: 705-715.

10. MacDonald J, Stuart E, Rodenberg R. Musculoskeletal Low Back Pain in School-aged Children: A Review. JAMA Pediatr 2017; 171: 280-287.

11. Yang S, Werner BC, Singla A, Abel MF. Low Back Pain in Adolescents: A 1-Year Analysis of Eventual Diagnoses. J Pediatr Orthop 2017; 37: 344-347.

12. Alaranta $H$, Luoto $S$, Heliövaara $M$, Hurri $H$. Static back endurance and the risk of low-back pain. Clin Biomech 1995; 10: 323-324.

13. Salminen JJ, Erkintalo M, Laine M, Pentti J. Low back pain in the young. A prospective three-year follow-up study of subjects with and without low back pain. Spine (Phila Pa 1976) 1995; 20: 2101-2107.

14. Allen BA, Hannon JC, Burns RD, Williams SM. Effect of a core conditioning intervention on tests of trunk muscular endurance in school-aged children. J Strength Cond Res 2014; 28: 2063-2070.

15. Dorneles RCG, Oliveira HLR, Bergmann MLA, Bergmann GG. Flexibility and muscle strength/resistance indicators and screening of low back pain in adolescents. Rev Bras Cineantropom Desempenho Hum 2016; 18: 93-102.
16. Saint-Maurice PF, Welk GJ, Burns R, Plowman SA, Corbin CB, Hannon JC. The criterion-referenced validity of the FITNESSGRAM Trunk-Extension test. J Sports Med Phys Fitness 2015; 55: 1252-1263.

17. Committee on Fitness Measures and Health Outcomes in Youth; Food and Nutrition Board; Institute of Medicine. Fitness measures and health outcomes in youth. Pate R, Oria M, Pillsbury L. (Ed.). Washington (DC): National Academies Press; 2012.

18. Sjolie AN. Low-back pain in adolescents is associated with poor hip mobility and high body mass index. Scand J Med Sci Sports. 2004; 14: 168-175.

19. Sjölie AN. Psychosocial correlates of low-back pain in adolescents. Eur Spine J 2002; 11: 582-588.

20. Kuorinka I, Jonsson B, Kilbom A, Vinterberg H, Biering-Sorensen F, Andersson G, et al. Standardised Nordic questionnaire for the analysis of musculoskeletal symptoms. Appl Ergon 1997; 18: 233-237.

21. Oliveira RG, Pires-Oliveira DAA, Oliveira LC, Remonte AK; Garcia SC, Araújo $\mathrm{CC}$, et al. Translation, transcultural adaptation and validation of the Nordic questionnaire for the evaluation of low back pain in Brazilian adolescents. Man Ther Posturology Rehabil J 2017, 15: 505

22. Cox JM. Low Back Pain: Mechanism, Diagnosis, and Treatment. 6th ed. Philadelphia: Williams \& Wilkins; 1999.

23. Fischer JE, Bachmann LM, Jaeschke R. A readers' guide to the interpretation of diagnostic test properties: clinical example of sepsis. Intensive Care Med 2003; 29: 1043-1051.

24. Welk GJ, Saint-Maurice PF, Csányi T. Health-Related Physical Fitness in Hungarian Youth: Age, Sex, and Regional Profiles. Res Q Exerc Sport 2015;86 Suppl 1: S45-57.

25. Scarabottolo CC, Pinto RZ, Oliveira CB, Zanuto EF, Cardoso JR, Christofaro DGD. Back and neck pain prevalence and their association with physical inactivity domains in adolescents. Eur Spine J 2017 (In Press).

26. Bortolini A, Jaeger D, Siqueira O, Crescente L, Garlipp D. Associação entre dores nas costas, flexibilidade e força/resistência abdominal em crianças e adolescentes. Cinergis 2016; 17: 231-234.

27. Guddal $M H$, Stensland $S \varnothing$, Småstuen $M C$, Johnsen MB, Zwart JA, Storheim K. Physical Activity Level and Sport Participation in Relation to Musculoskeletal Pain in a Population-Based Study of Adolescents: The Young-HUNT Study. Orthop J Sports Med 2017; 5: 2325967116685543.

28. Aartun E, Boyle E, Hartvigsen J, Ferreira PH, Maher CG, Ferreira ML, Hestbaek $L$. The most physically active Danish adolescents are at increased risk for developing spinal pain: a two-year prospective cohort study. BMJ Open Sport Exerc Med 2016; 2: e000097. 